\title{
A New Class of Draw Solutions for Minimizing Reverse Salt Flux to Improve Forward Osmosis Desalination
}

\author{
Hau Thi Nguyen ${ }^{\mathrm{a}}$, Nguyen Cong Nguyen ${ }^{\mathrm{a}}$, Shiao-Shing Chen ${ }^{\mathrm{a}^{*}}$, Huu Hao Ngo ${ }^{\mathrm{b}^{*}}$, Wenshan \\ Guo $^{\mathrm{b}}$, Chi-Wang Li ${ }^{\mathrm{c}}$ \\ ${ }^{a}$ Institute of Environmental Engineering and Management, National Taipei University \\ of Technology, No.1, Sec. 3, Chung -Hsiao E. Rd, Taipei 106, Taiwan, ROC \\ ${ }^{b}$ Centre for Technology in Water and Wastewater, School of Civil and Environmental \\ Engineering, University of Technology, Sydney, Broadway, NSW 2007, Australia \\ ${ }^{c}$ Department of Water Resources and Environmental Engineering, TamKang University, \\ 151 Yingzhuan Road, Tamsui District, New Taipei City 25137, Taiwan, ROC \\ *Corresponding authors: \\ E-mail address: f10919@ntut.edu.tw (Shiao-Shing Chen) \\ E-mail address: h.ngo@uts.edu.au (Huu Hao Ngo)
}

\begin{abstract}
The applications of forward osmosis (FO) have been hindered because of the lack of an optimal draw solution. The reverse salt flux from the draw solution not only reduces the water flux but also increases the cost of draw solute replenishment. Therefore, in this study, Tergitol NP7 and NP9 with a long straight carbon chain and low critical micelle concentration (CMC) were coupled with highly charged ethylenediaminetetraacetic acid (EDTA) as an innovative draw solution to minimize reverse salt diffusion in FO for the first time. The results showed that the lowest reverse salt flux of $0.067 \mathrm{GMH}$ was observed when 0.1 M EDTA-2Na coupled with 15 mM NP7 was used as a draw solution and deionized water was used as a feed solution. This is because of the hydrophobic interaction between the tails of NP7 and the FO membrane, thus creating layers on the membrane surface and constricting the FO membrane pores. Moreover, 1 M EDTA-2Na coupled with $15 \mathrm{mM} \mathrm{NP7}$ is promising as an optimal draw solution for brackish water and sea water desalination. Average water fluxes of 7.68, 6.78, and 5.95 LMH were achieved when brackish water was used as a feed solution $(5,10$, and $20 \mathrm{~g} / \mathrm{L} \mathrm{NaCl})$, and an average water flux of 3.81 LMH was achieved when sea water was used as a feed solution (35 $\mathrm{g} / \mathrm{L} \mathrm{NaCl}$ ). The diluted draw solution was recovered using a nanofiltration (NF-TS80) membrane with a high efficiency of $95 \%$ because of the high charge and large size of the draw solution.
\end{abstract}

Key words: forward osmosis; draw solution; water flux; reverse salt flux. 


\section{Introduction}

Forward osmosis (FO) is a valuable technology with a low operating cost and is used for wastewater treatment [1], brackish water and seawater desalination [2], food processing [3,4], and power generation $[5,6]$. In FO, the energy required to transport water across the membrane is negligible because of the absence of hydraulic pressure. Typically, selecting a semipermeable membrane and a suitable draw solution are crucial for attaining high FO system performance [7]. Recently, considerable efforts have focused on developing a novel draw solution to meet the following requirements: (1) high water flux; (2) low reverse salt diffusion; and (3) easy recovery of the diluted draw solution [7, 8]. However, the high salt leakage and high energy consumption involved in recovering the diluted draw solution are major challenges that restrict the development of FO.

During the last few years, most studies have investigated the used of inorganic salts as draw solutions because of their low cost and high osmotic pressure potential, which creates a high water flux $[9,10]$. However, the low charge and small hydrated radius of monovalent and divalent ions in the draw solution can result in a high reverse flux of salts, such as $0.6 \mathrm{M} \mathrm{NaCl}\left(\mathrm{J}_{\mathrm{s}}\right.$ $=7.2 \mathrm{GMH}), 0.6 \mathrm{M} \mathrm{NH}_{4} \mathrm{HCO}_{3}\left(\mathrm{~J}_{\mathrm{s}}=18.2 \mathrm{GMH}\right)$, or $0.5 \mathrm{M} \mathrm{MgCl}_{2}\left(\mathrm{~J}_{\mathrm{s}}=5.6 \mathrm{GMH}\right)$, when deionized (DI) water was used as the feed solution [11]. In addition, recovering these draw solutions requires a high amount of energy because the pressure-driven reverse osmosis (RO) membrane is still required to recover water from the salts [12] or the standard of the water obtained is not close to that of drinking water. This is caused by the leakage of a high amount of ammonium bicarbonate into water [7]. To overcome these disadvantages of inorganic salts, magnetic nanoparticles (MNPs) were synthesized and used as a smart draw solution, and no reverse salt flux occurred. However, particle agglomeration was observed during recycling through a magnetic separator, and the FO performance deteriorated accordingly $[13,14]$. In addition, the synthesis of MNPs is complicated and difficult.

Furthermore, other materials have been used for FO, such as the polyelectrolyte of polyacrylic acid sodium salts [15], 2-methylimidazole-based organic compounds [16], switchable polarity solvents [17], ferric and cobaltous hydro acid complexes [18], dimethyl ether solutions [19], and poly (sodium 4-styrenesulfonate) [20]. These draw solutions showed justifiable water flux. However, high reverse salt flux and relatively energy-intensive regeneration make them impractical in FO desalination. Therefore, identifying novel draw solutes with characteristics of high water flux, low reverse salt flux, and easy recovery is necessary.

Among the currently used draw solutions, ethylenediaminetetraacetic acid (EDTA)-2Na not only has a high water flux and low reverse salt diffusion but also can be recovered relatively easily by using a nanofiltration (NF-TS80) membrane, as demonstrated in our previous study [21]. To increase efficiency with minimal salt leakage, nonylphenol ethoxylates (Tergitol NP7 and NP9) were combined with EDTA-2Na. Nonylphenol ethoxylate with an expanded structure, long straight carbon chain, and low critical micelle concentration (CMC) created layers on the 
membrane surface, thus constricting the membrane pores to minimize reverse salt diffusion. Moreover, the coupling of the surfactant with EDTA-2Na formed the large size of particles in the draw solution, therefore it was easily recovered using the NF membrane [22].

The effect of coupling NP7 and NP9 nonionic surfactants with EDTA-2Na on the reverse salt flux and water flux were investigated under the following conditions: (1) various surfactant concentrations; (2) various EDTA-2Na concentrations; (3) desalination; and (4) recovery of the diluted draw solution by using the NF membrane. The results demonstrated that combining EDTA-2Na with NP7 and NP9 can significantly reduce the reverse salt flux and improve the recovery efficiency of the diluted draw solution in FO desalination processes. To our best knowledge, any use of draw solution based on coupling NP7 and NP9 with EDTA-2Na for FO performance has not been published up to now.

\section{Material and method}

\subsection{Materials}

A thin-film composite membrane was supplied by Hydration Technology Innovations (Albany, Oregon, USA). The FO membrane is relatively hydrophobic with a measured contact angle of approximately $70^{\circ}$ and thickness of less than $50 \mu \mathrm{m}$ [23]. Moreover, it has a negative charge with a mean pore radius of $0.37 \mathrm{~nm}$ [24]. Laboratory-grade EDTA-2Na (purity of 99.0\%) was purchased from Sigma-Aldrich Corporation, Germany. Nonylphenol ethoxylate surfactants, Tergitol NP7 and NP9, were supplied by the Dow Chemical Company, Midland (Albany, Oregon, USA). The average molecular weight is $600 \mathrm{~g} / \mathrm{mol}$, the molecular formula is $\mathrm{C}_{15} \mathrm{H}_{24} \mathrm{O}\left(\mathrm{C}_{2} \mathrm{H}_{4} \mathrm{O}\right)_{\mathrm{x}}$, and the CMCs of NP7 and NP9 at $25{ }^{\circ} \mathrm{C}$ are 39 and $60 \mathrm{ppm}$, respectively [25]. EDTA-2Na coupled with the surfactants was controlled at $\mathrm{pH} 8$ before FO tests [21]. In FO experiments, DI water, brackish water $(5 \mathrm{~g} / \mathrm{L}, 10 \mathrm{~g} / \mathrm{L}$, and $20 \mathrm{~g} / \mathrm{L} \mathrm{NaCl})$, and seawater $(35 \mathrm{~g} / \mathrm{L}$ $\mathrm{NaCl}$ ) were used as the feed solution. The NF membrane NF-TS80 was used to recover the draw solution (EDTA-2Na combined with anonionic surfactant).

Table. 1. Structures of EDTA-2Na and nonylphenol ethoxylate surfactant

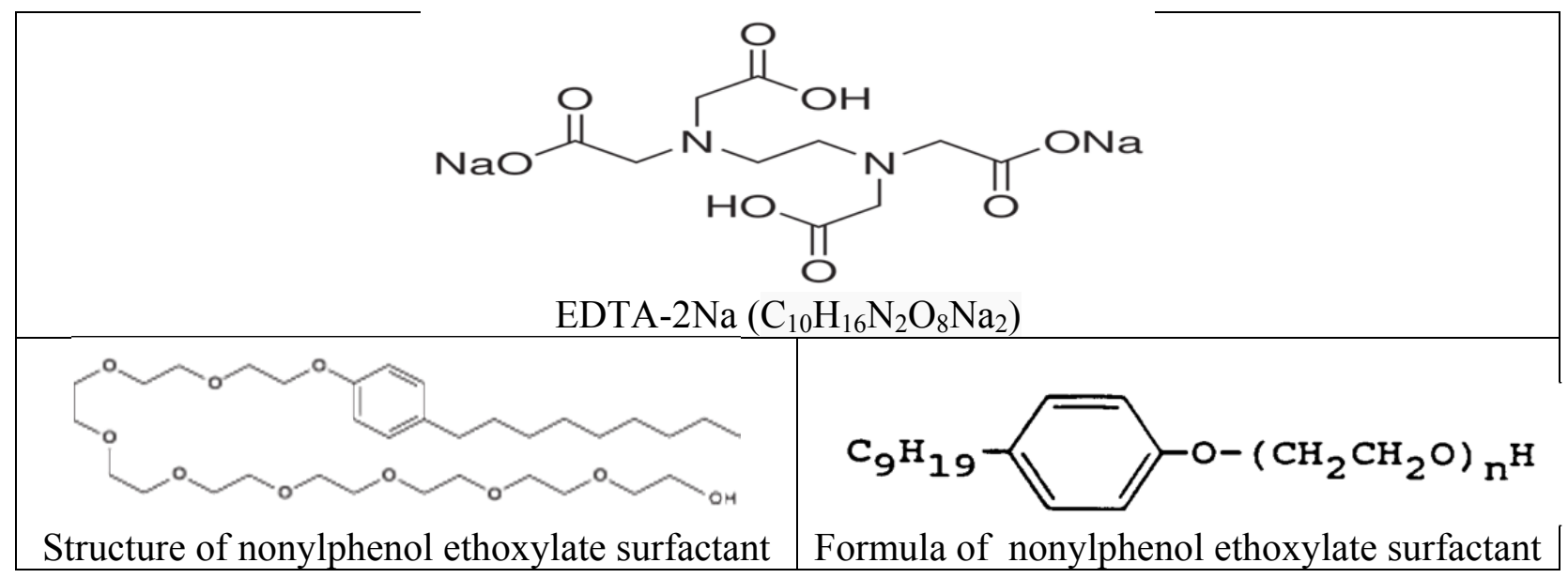


The structures of EDTA-2Na and nonylphenol ethoxylate surfactants are provided in Table 1. The formation of a highly charged species of EDTA that could generate a high water flux with minimal reverse salt diffusion depends on the $\mathrm{pH}$. In addition, the carboxyl group of EDTA-2Na complexes easily with $\mathrm{Na}^{+}$ions can be attributed to the reduction in reverse salt diffusion. The nonylphenol ethoxylate surfactants NP7 and NP9, which have long and straight carbon chains, can be coupled with EDTA-2Na to maintain minimal reverse transport. Furthermore, this combination could increase the size of particles in the draw solution, leading to a recovery efficiency of the diluted draw solution as high as $95 \%$.

2.2 Measurement of water flux, reverse solute flux and solute rejection

Theoretical water flux $\left(\mathrm{J}_{\mathrm{w}}(\mathrm{LMH})\right)$ across the $\mathrm{FO}$ membrane was calculated from the volume change of feed solution follow equation (1)

$$
J_{w}=\frac{\Delta V}{A \Delta t}
$$

Where $\Delta \mathrm{V}(\mathrm{L})$ is the volume change of feed solution over a predetermined time $\Delta t(h)$, and $A$ is the effective FO membrane surface area $\left(\mathrm{m}^{2}\right)$

The calibrated conductivity meter (Oakton Instruments, Vernon Hills, IL) was used to measure the conductivity in the feed tank. All the conductivities measured from the feed solution were converted in the range of the standard curve which was built from a series of single solutions and indicated the relationship of conductivity and concentration. The concentration of the draw solution transporting to the feed solution was thereafter obtained directly from the standard curve. The reverse solutes flux $\left(\mathrm{J}_{\mathrm{s}}(\mathrm{GMH})\right)$ was determined from the concentration increase of the feed solution as follow equation (2)

$$
J_{s}=\frac{C_{t} V_{t}-C_{0} V_{0}}{A \Delta t}
$$

Where, $\mathrm{C}_{0}(\mathrm{~g} / \mathrm{L})$ and $\mathrm{V}_{0}(\mathrm{~L})$ are the initial concentration and initial volume of the feed solution, respectively, and $\mathrm{C}_{\mathrm{t}}(\mathrm{g} / \mathrm{L})$ and $\mathrm{V}_{\mathrm{t}}(\mathrm{L})$ are the solutes concentration and the volume of the feed solution measured at time of $\mathrm{t}$, respectively.

Specific reverse salt flux $\left(J_{s} / J_{w}(g / L)\right)$ is defined as the ratio of the salt flux $\left(J_{s}(G M H)\right)$ in the reverse direction to the water flux $\left(J_{w}(L M H)\right)$ in the forward direction and is used to estimate the amount of the draw solute lost per liter of the water produced during FO. Moreover, this ratio is related to the water-salt selectivity of the membrane. Specific reverse salt flux was quantified through experiments in which DI water was used as the feed solution and the concentration of the draw solute was varied. 
A thin film composite polyamide nanofiltration membrane (NF-TS80) was used for the draw solution recovery under an $80 \mathrm{psi}$ gas pressure. The solute rejection is calculated follow equation (3)

$$
R=\left(1-\frac{C_{P}}{C_{F}}\right) \times 100 \%(3)
$$

Where $R$ is solute rejection, $C_{P}(m g / L)$ is the permeate concentration, $C_{F}(m g / L)$ is the solute concentration in the feed solution calculated from the difference of the initial solution concentration and the permeate concentration.

\subsection{Experiment setup}

The experimental setup is shown in Figure 1 (a) and (b). The feed and draw solutions on both sides of the FO membrane were circulated using two peristaltic pumps, and two water baths were used to control the temperature at $25 \pm 0.5{ }^{\circ} \mathrm{C}$. Conductivity and $\mathrm{pH}$ sensors were installed in the containers of the feed and draw solutions to monitor any changes. The volume of the draw solution was $4 \mathrm{~L}$, and a $2 \mathrm{~L}$ feed solution tank was placed on a digital scale (BW12KH, Shimadzu, Japan) that was connected to a computer data logging system to monitor the weight and volume changes at specified time intervals. After FO tests, the diluted draw solution was recovered for reuse through the NF-TS80 membrane by using a cross flow module (CF042 DelrinAcetal Cross flow Cell, USA) at operating hydraulic pressures of 80 psi. All experimental data were collected after $1 \mathrm{~h}$ to prevent the adsorption of ions on the membrane surface from influencing the results.

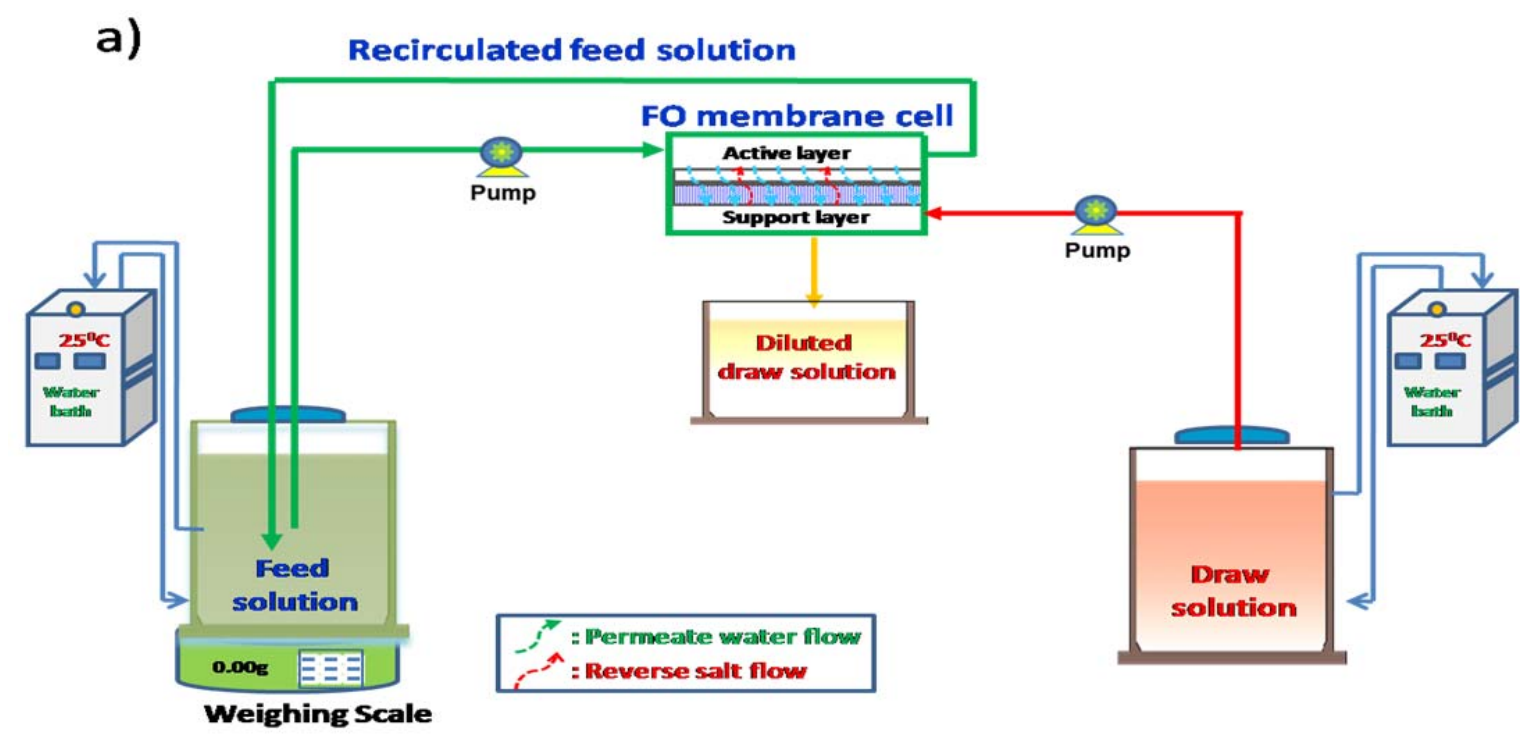




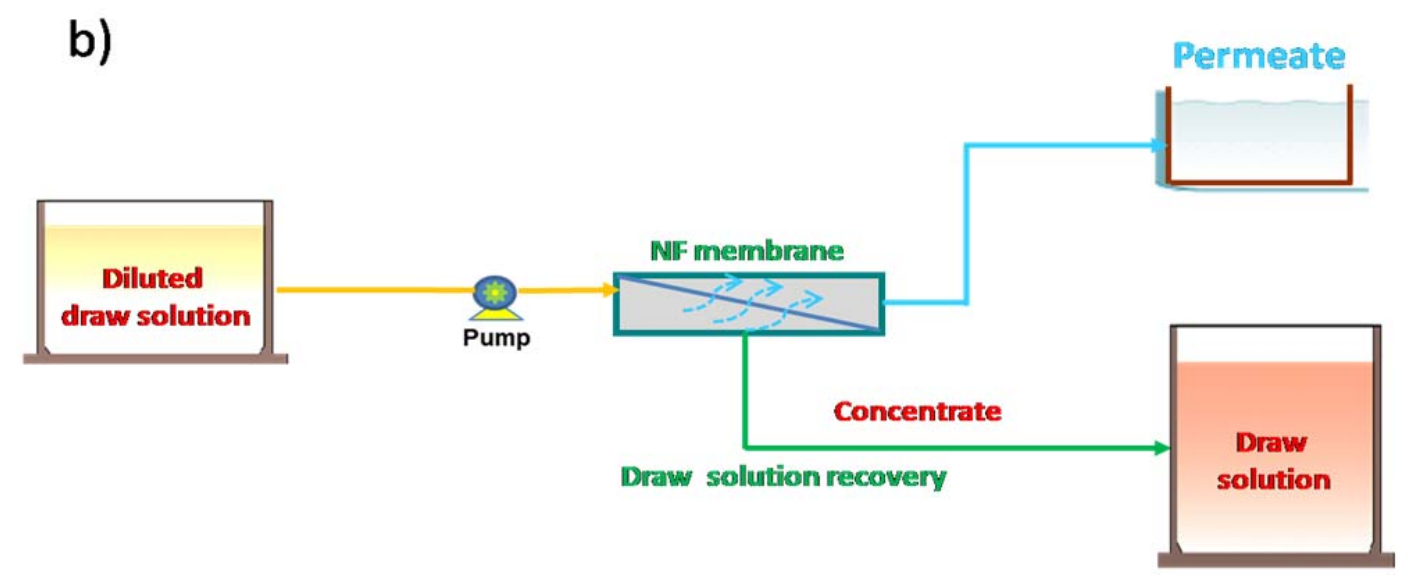

Figure. 1. (a) Schematic diagram of the lab-scale FO system and (b) the recovery of diluted draw solution through NF system.

\subsection{Analytical methods}

The $\mathrm{pH}$ of the draw solution was determined using a $\mathrm{pH}$ meter (Horiba $\mathrm{pH}$ meter D-54, Japan). The $\mathrm{Na}^{+}$ion concentration was analyzed using ion chromatography (DionexICS-90). The osmolality of draw solutions was measured using an osmometer (Model 3320, Advanced Instruments, Inc., USA). The measured osmolality of the solutions was then converted to osmotic pressure by using the Morse equation as follows:

$\pi=\left(\sum \phi n C\right) R T$,

where $\left(\sum \phi \cap C\right)$ represents total osmolality, $R$ is the universal gas constant, and $T$ is the absolute temperature.

The viscosity and conductivity were determined using the Vibro Viscometer (AD Company, Japan) and a conductivity meter (Sension156, Hach, China), respectively. The size of particles in the draw solution was measured using the SZ-100 nanoparticle analyzer (Horiba, Japan). The concentrations of each solute in the feed solution and permeation were detected using a total organic carbon (TOC) analyzer (ASI-5000A, Shimadzu, Japan).

\section{Results and discussion}

3.1 Effect of various surfactant concentrations on reverse salt flux and water flux

The NP7 surfactant was added to EDTA-2Na in various concentrations $(0,1.6,7.5,15$, and 30 $\mathrm{mM}$ ). Coupling EDTA-2Na with NP7 reduced the reverse salt flux compared with using EDTA$2 \mathrm{Na}$ alone because of the hydrophobic interaction effect. In particular, when 0.1 M EDTA-2Na was coupled with 15-30 mM NP7, the reverse salt flux decreased significantly to $0.067 \mathrm{GMH}$. This is the most crucial finding. The decrease occurred because EDTA consists of 98.2\% $\mathrm{H}[\mathrm{EDTA}]^{3-}$ and $1.8 \% \mathrm{H}_{2}$ [EDTA $^{2-}$ at $\mathrm{pH} 8$ (Figure 3), and these trivalent and divalent ions were 
retained on the $\mathrm{FO}$ membrane because of the repulsion force between the negatively charged FO membrane and negatively charged $\mathrm{H}[\mathrm{EDTA}]^{3-}$ and $\mathrm{H}_{2}[\mathrm{EDTA}]^{2-}$, reducing reverse salt flux.

Moreover, when NP7 was coupled with EDTA-2Na, the adsorption of NP7 on the membrane through a hydrophobic interaction between the hydrophobic tail of the surfactant and the hydrophobic membrane constricted the membrane pores, leading to a significant reduction in the reverse salt diffusion of $\mathrm{Na}^{+}, \mathrm{H}_{2}[\mathrm{EDTA}]^{2-}$, and $\mathrm{H}[\mathrm{EDTA}]^{3-}$ (Figure 4) [26]. This is similar to the hydrophobic interactions between selected pharmaceuticals and FO membranes, which served as the dominant removal mechanism, demonstrated by Jin et al.[27].

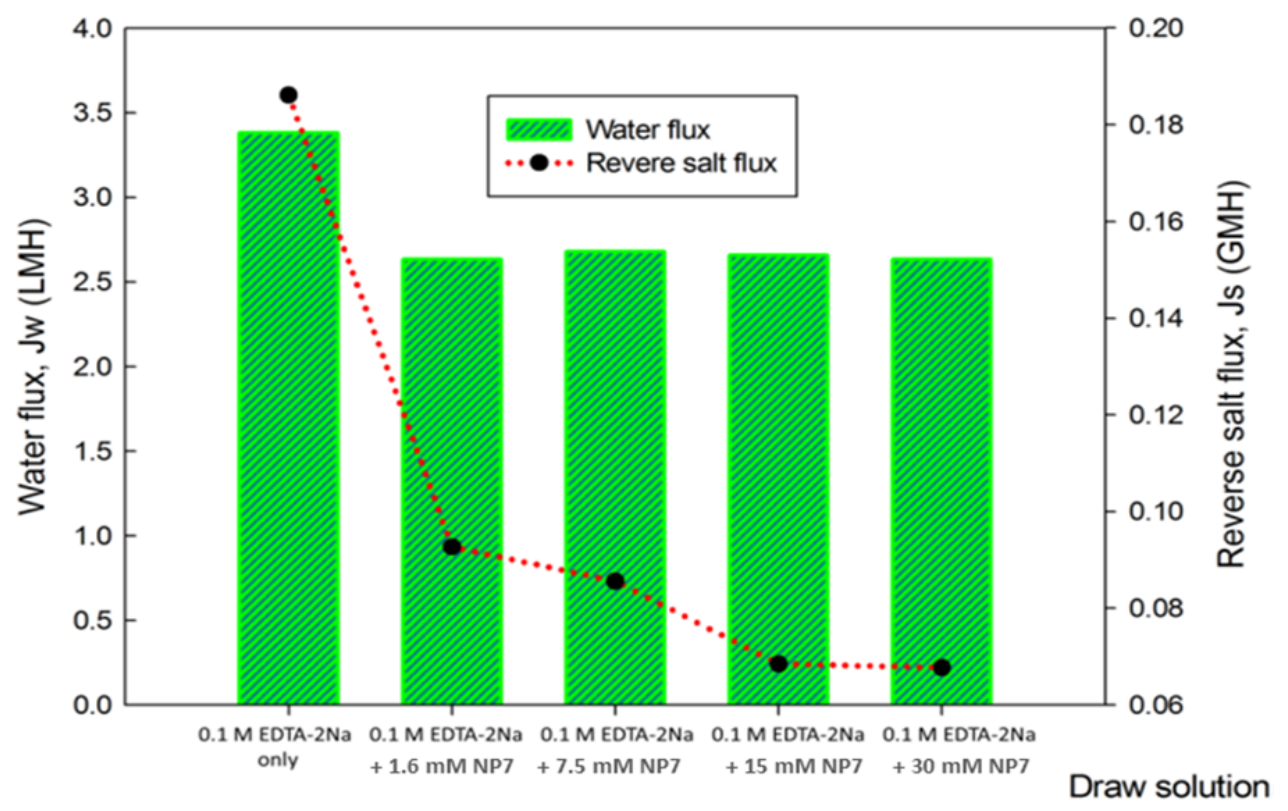

Figure. 2. Variation of reverse salt flux and water flux using EDTA-2Na coupled with NP7 as draw solution (draw solution facing support layer, DI water as the feed solution)

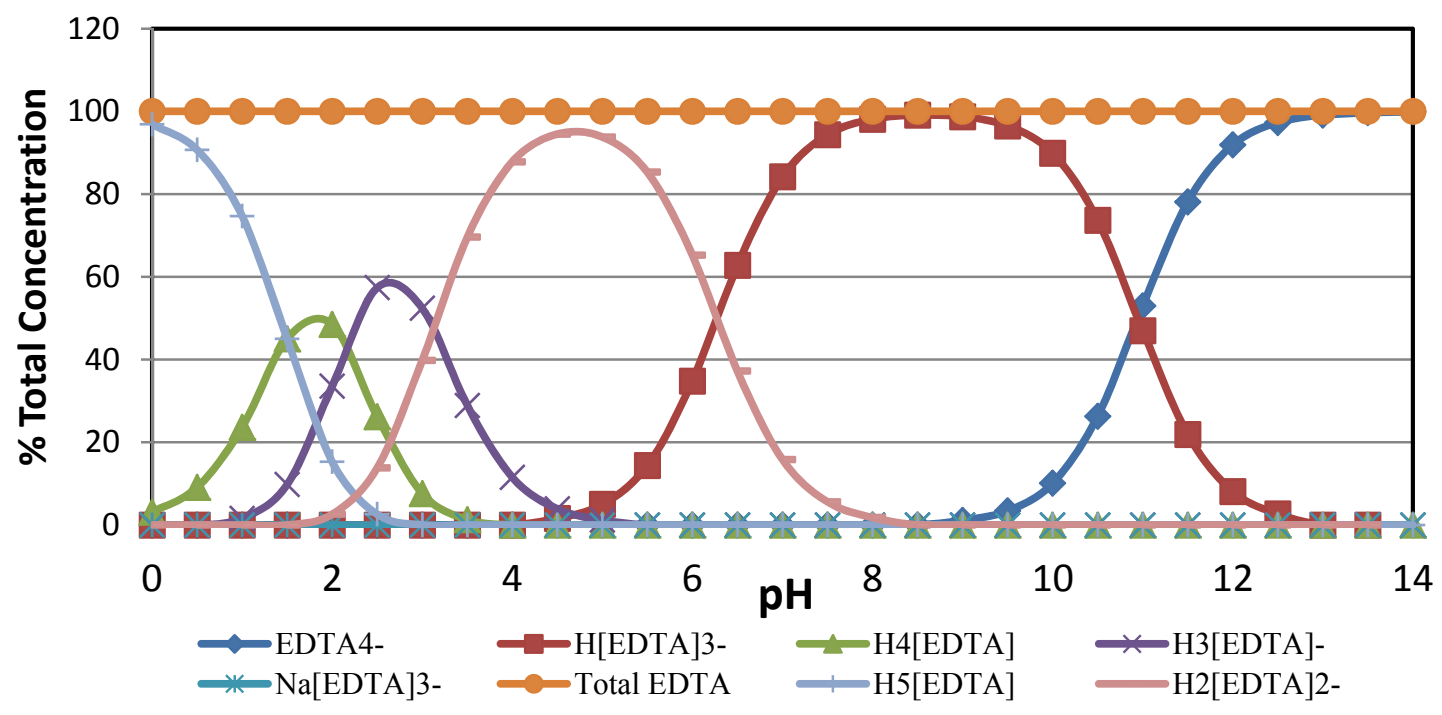


Figure. 3. Complex formation for $0.1 \mathrm{M}$ EDTA $+0.097 \mathrm{M} \mathrm{NaOH}$ concentration (reproduced from the data of Mineql+)
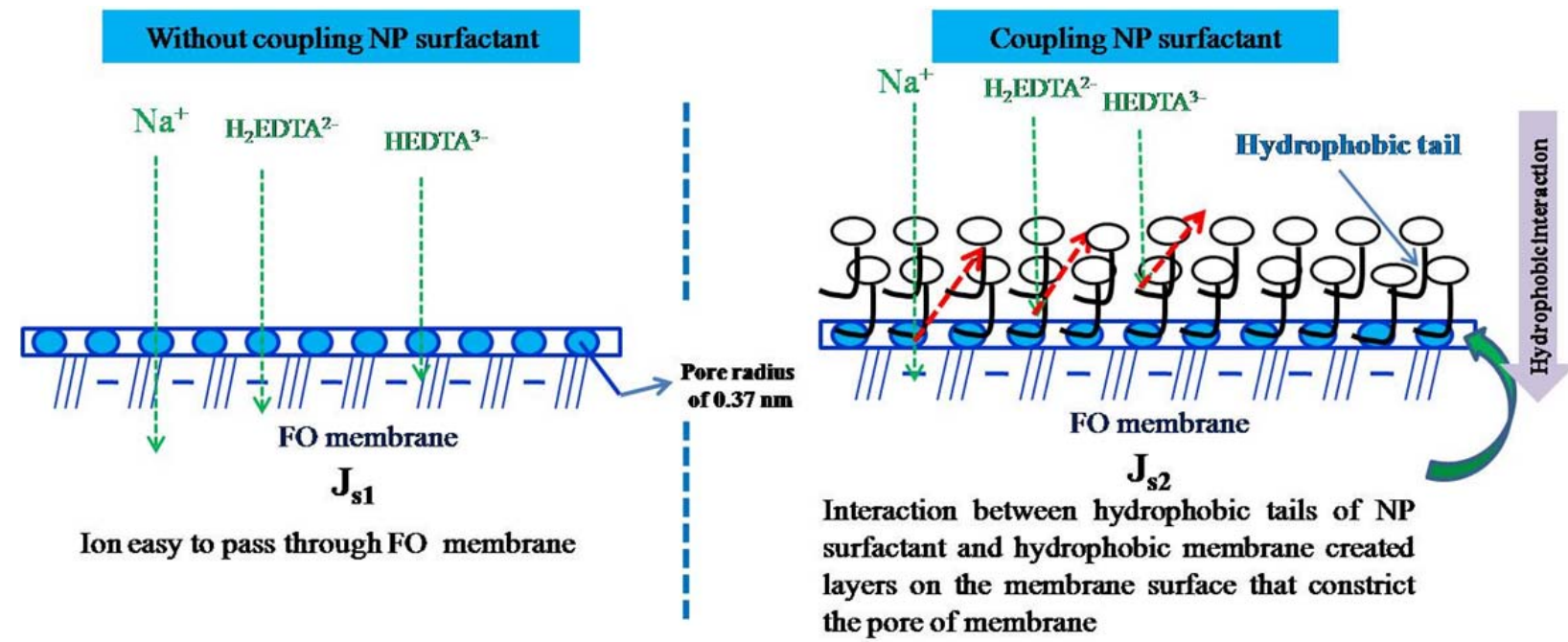

\section{Reverse salt flux $\mathbf{J}_{\mathbf{s} 1} \gg \mathbf{J}_{\mathbf{s} 2}$}

Figure. 4. Schematic illustration for reduce diffusion of ions with presence of nonionic surfactant in draw solution

Figure 5 (a) shows the effect of increasing the surfactant concentration on the osmotic pressure and viscosity of the draw solution. The osmotic pressure slightly increased from 6.98 to 7.31 bars when the NP7 concentration was increased from 0 to $30 \mathrm{mM}$. In addition, the viscosity of the draw solution increased with an increase in the NP7 concentration. This phenomenon contributes to the reduction in the water flux because of the effect of the viscosity of the draw solution and the formation of a thick layer on the FO membrane surface. As shown in Figure 5 (b), the TOC and specific reverse salt flux decreased considerably with an increase in the NP7 concentration. These results demonstrate that a low TOC and low specific reverse salt flux are directly related to FO because they lead to a low reverse solute flux.
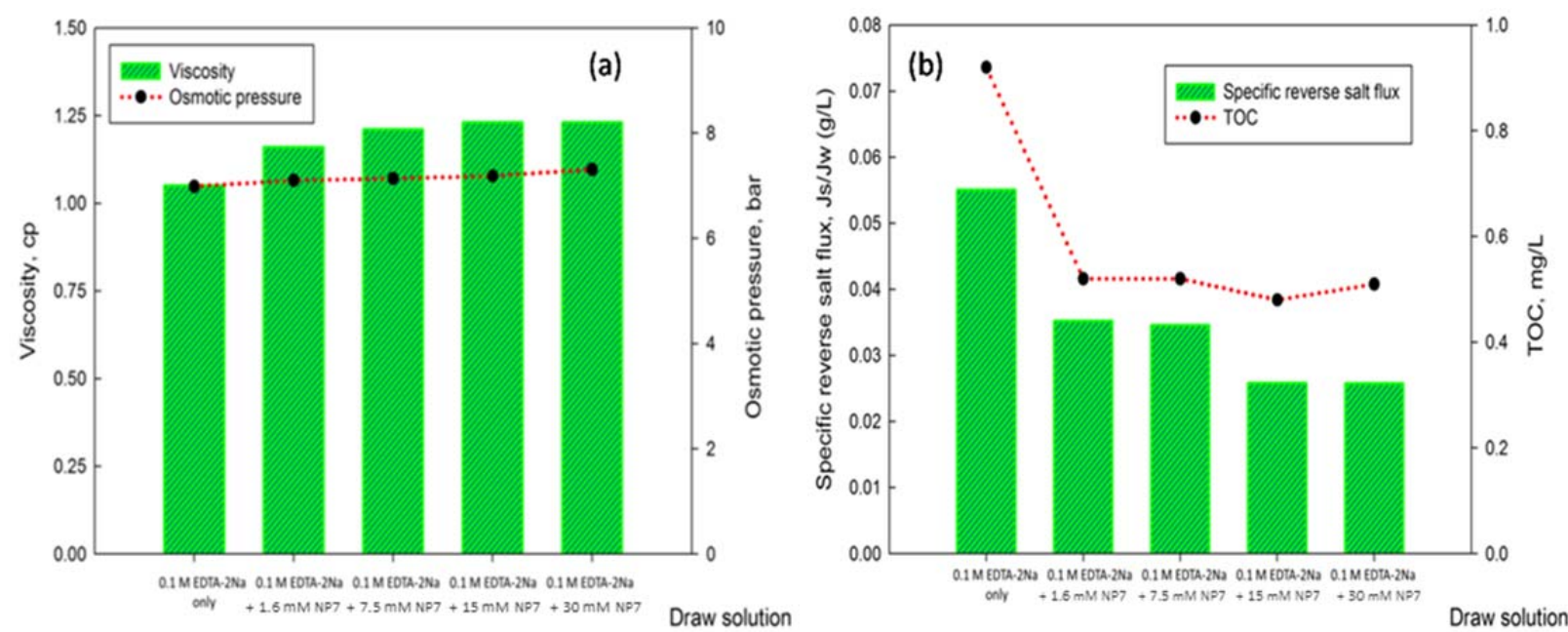
Figure. 5. (a) Viscosity and osmotic pressure and (b) specific reverse salt flux and TOC from EDTA-2Na coupled with NP7 (draw solution facing support layer, DI water as the feed solution)

In addition, NP9 was coupled with EDTA-2Na, and the results were compared with those obtained when NP7 was coupled with EDTA-2Na in the same concentration range. The results showed that the reverse salt flux decreased considerably (Figure 6 (a)). However, a higher reverse salt diffusion was obtained. For example, the reverse salt flux of $0.1 \mathrm{M}$ EDTA-2Na coupled with $15 \mathrm{mM} \mathrm{NP7}$ was $0.067 \mathrm{GMH}$ and that of $0.1 \mathrm{M}$ EDTA-2Na coupled with $15 \mathrm{mM}$ NP9 was 0.092 GMH. Furthermore, NP9, which has a higher CMC, exhibited more reverse transport than NP7, which has a lower CMC [22]. The osmotic pressure of the draw solution slightly increased and the viscosity increased rapidly with an increase in the NP9 concentration (Figure 6 (b)). In addition, the specific reverse salt flux decreased when EDTA-2Na was coupled with NP9 (Figure 6 (c)). Thus, EDTA-2Na coupled with NP9 had a lower efficiency than that of EDTA-2Na coupled with NP7 because of the higher reverse salt flux.
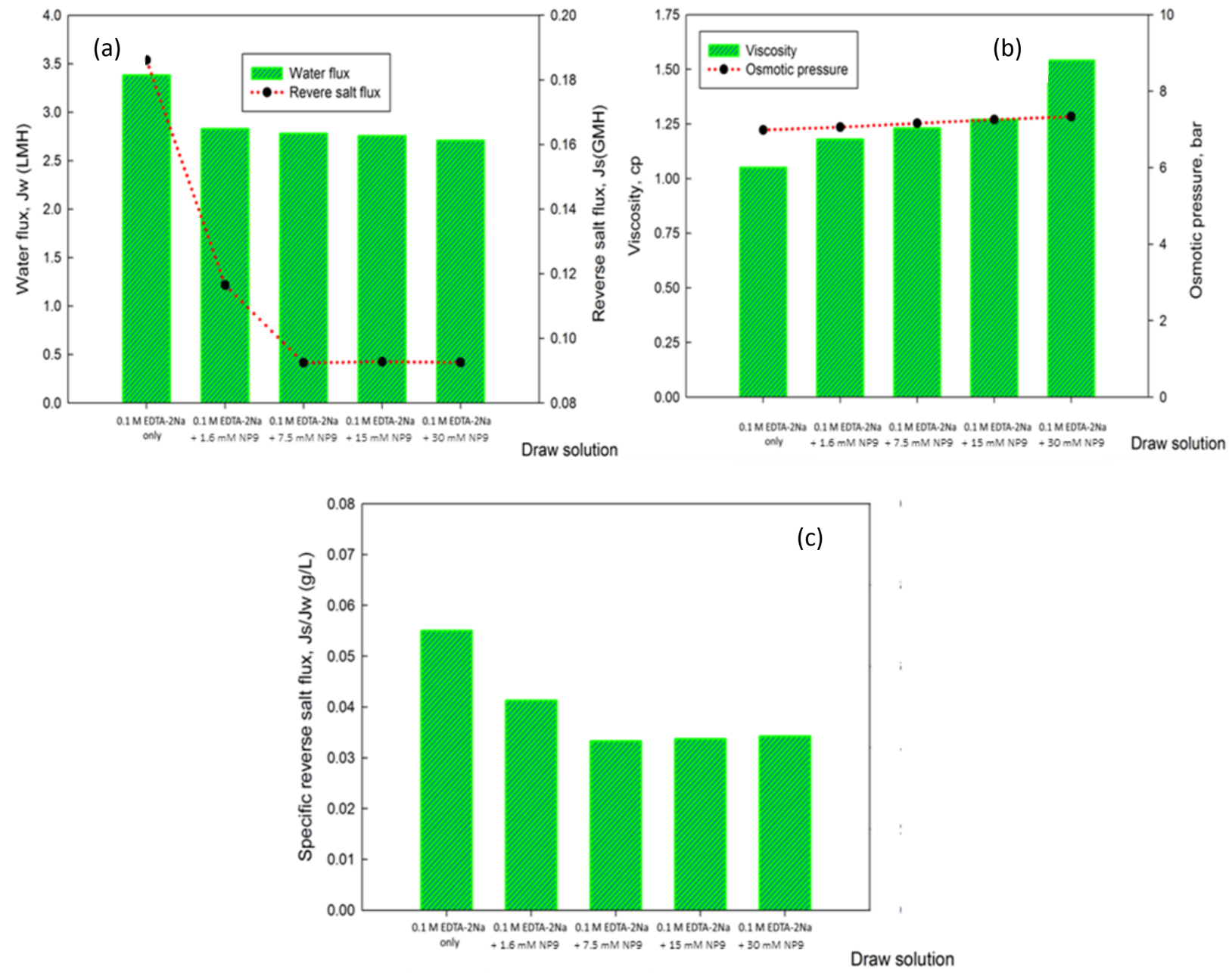
Figure. 6. (a) Variation of reverse salt flux and water flux, (b) viscosity and osmotic pressure and (c) specific reverse salt flux from EDTA-2Na coupled with NP9 (draw solution facing support layer, DI water as feed solution)

\subsection{Effect of various EDTA-2Na concentrations on water flux and reverse salt flux}

The aforementioned results demonstrated that NP7 coupled with EDTA-2Na could achieve a lower reverse salt flux than NP9 coupled with EDTA-2Na. Therefore, EDTA-2Na at various concentrations $(0.1,0.2,0.4,0.6,0.8$, and $1 \mathrm{M})$ was coupled with $15 \mathrm{mM} \mathrm{NP7}$ at $\mathrm{pH} 8$. Figure 7 shows the water flux and reverse salt flux when DI water was used as the feed solution. The results showed that the water flux increased rapidly from 2.65 to $8.8 \mathrm{LMH}$ when the EDTA-2Na concentration was increased from 0.1 to $1 \mathrm{M}$. This is because of an increase in the osmotic pressure from 7.16 to 59.46 bars when the EDTA-2Na concentration was increased. The concentration polarization (CP) of the membrane can be contributed to the nonlinear of the increase in the water flux. The CP reduced the water flux by approximately 2-7 times relative to the theoretical water flux $[10,28]$.

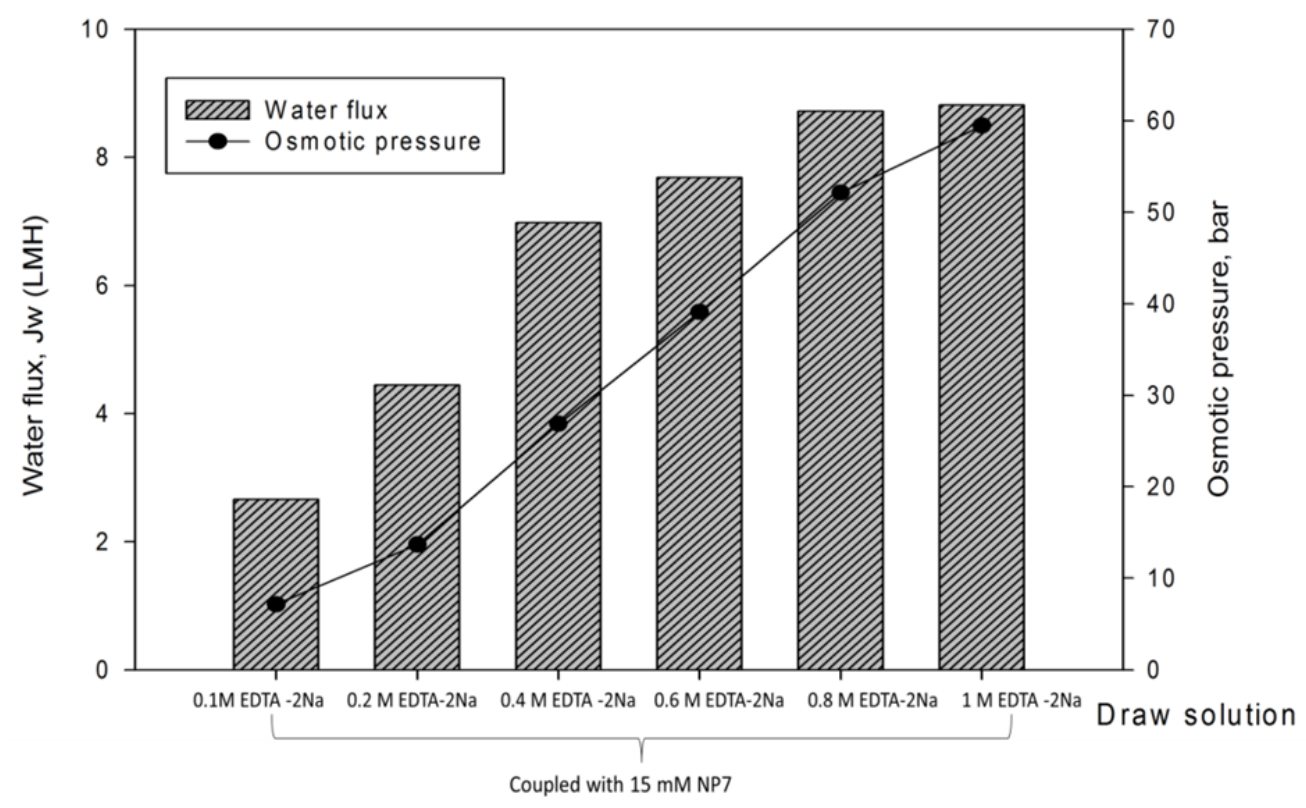

Figure. 7. Effect of various EDTA-2Na concentrations coupled with $15 \mathrm{mM} \mathrm{NP7}$ on reverse salt flux and water flux

Figure 8 shows that the TOC and specific reverse salt flux increased with an increase in the EDTA-2Na concentration. The increase in the specific reverse salt flux can be attributed to an increase in $\mathrm{Na}^{+}, \mathrm{H}[\mathrm{EDTA}]^{3-}$, or $\mathrm{H}_{2}[\mathrm{EDTA}]^{2-}$, thus increasing the TOC. 


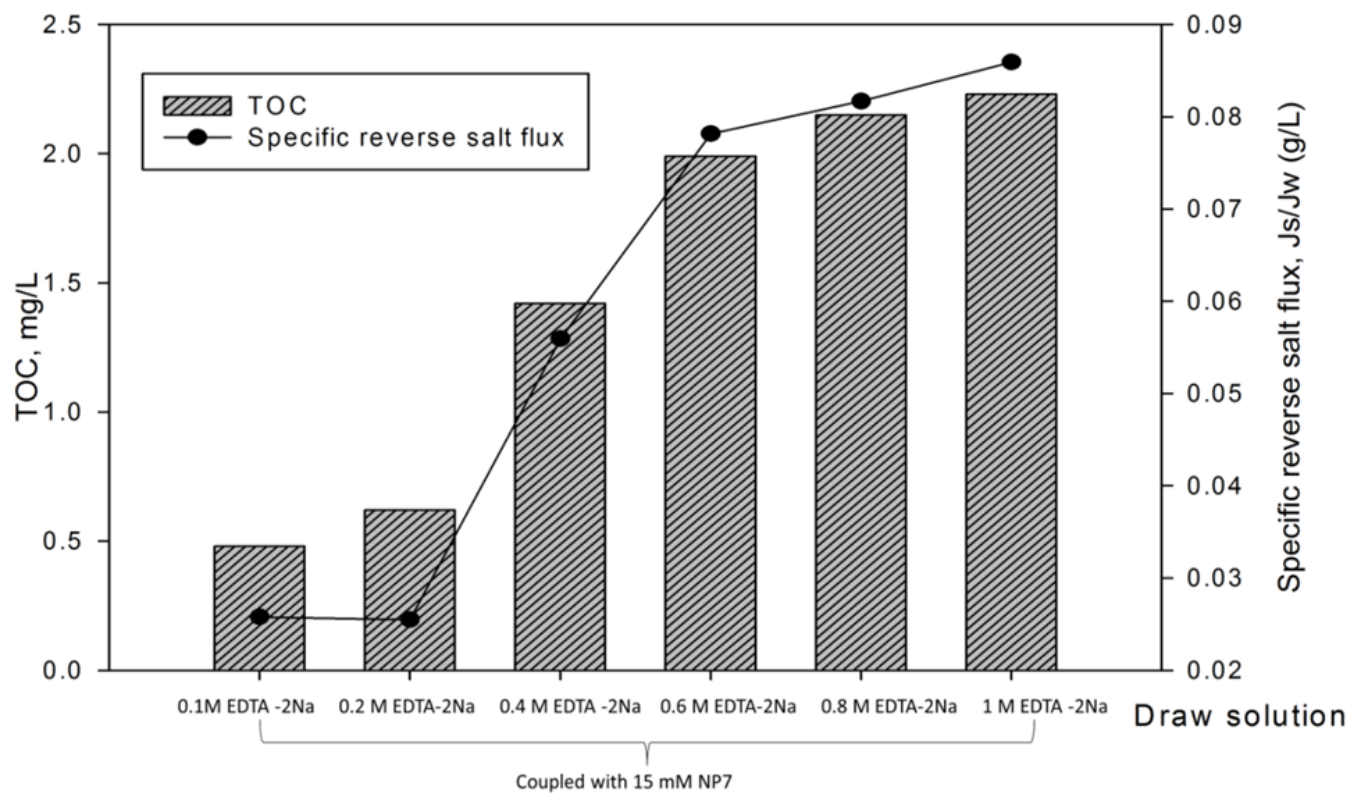

Figure. 8. Effect of various EDTA-2Na concentrations coupled with $15 \mathrm{mM} \mathrm{NP7}$ on TOC and specific reverse salt flux

3.3 Desalination processes using 1M EDTA-2Na coupled with $15 \mathrm{mM} \mathrm{NP7}$ as draw solution

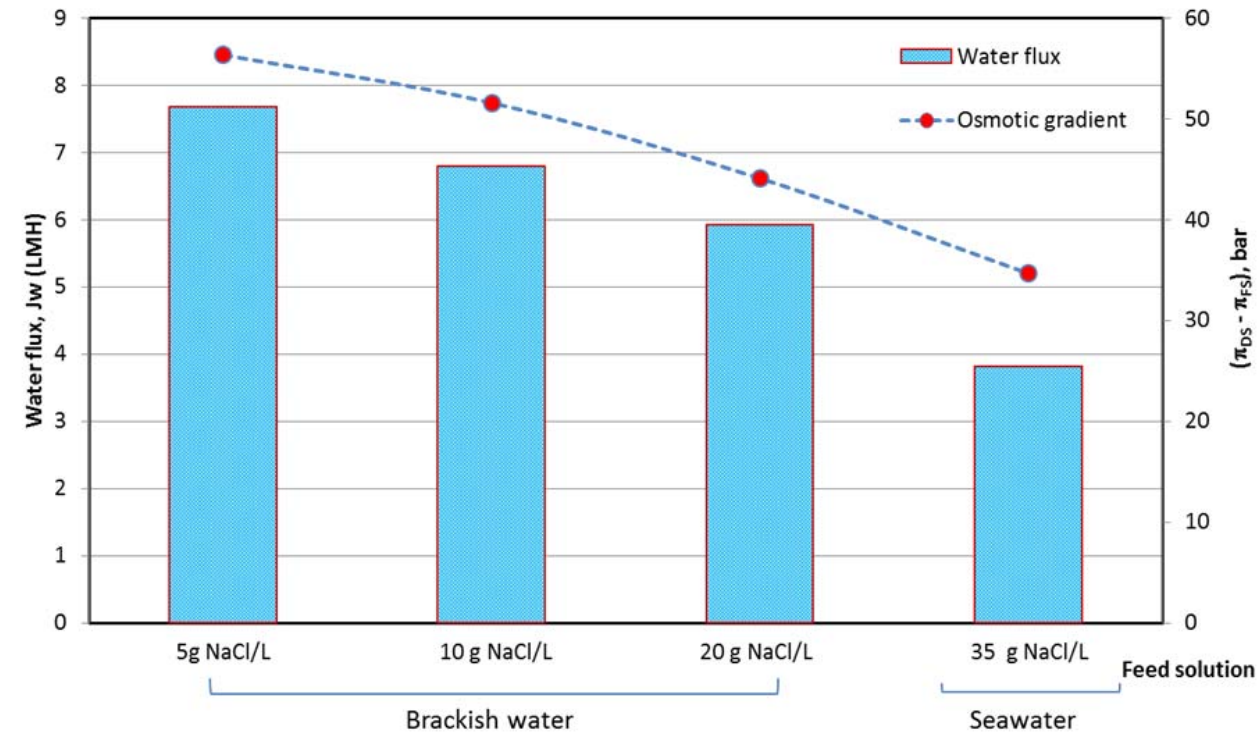

Figure.9. Various water flux via different feed solution using 1 M EDTA-2Na coupled with 15 mM NP7 as draw solution, brackish water and seawater as feed solution (membrane orientation of draw solution facing support layer, flow rate of $500 \mathrm{~mL} / \mathrm{min}$, temperature of $25 \pm 0.5{ }^{0} \mathrm{C}, \mathrm{pH}$ 8) 
As shown in Figure 9, brackish water with 5, 10, and $20 \mathrm{~g} / \mathrm{L} \mathrm{NaCl}$ exhibited water fluxes of 7.68, 6.78, and 5.95 LMH, respectively, which are higher than that of seawater (3.81 LMH). The results indicated that the water flux decreased considerably when brackish water and seawater replaced DI water as the feed solution because the osmotic pressure exerted by brackish water and seawater reduced the net driving force across the membrane, leading to a reduction in the water flux [4, 29]. However, $1 \mathrm{M}$ EDTA-2Na coupled with $15 \mathrm{mM}$ NP7 as the draw solution demonstrated excellent performance in FO desalination with high water flux and minimal reverse salt flux.

\subsection{Recovery of draw solution using NF-TS80 membrane}

Table.2. Recovery efficient of draw solution using NF-TS80 membrane

\begin{tabular}{cccccc}
\hline & \multicolumn{2}{c}{0.05 M EDTA-2Na only } & \multicolumn{3}{c}{0.05 M EDTA-2Na coupled with 15 mM NP7 } \\
\hline TDS input, & TDS permeate & Removal & TDS input & TDS permeate & Removal \\
$(\mathrm{ppm})$ & $(\mathrm{ppm})$ & efficiency $(\%)$ & $(\mathrm{ppm})$ & $(\mathrm{ppm})$ & efficiency $(\%)$ \\
\hline $6970 \pm 12$ & $624 \pm 12$ & $91.04 \pm 0.15$ & $6900 \pm 10$ & $359 \pm 10$ & $94.8 \pm 0.17$ \\
\hline
\end{tabular}

After FO, the draw solution is diluted; therefore, draw solution recovery is necessary and represents one of the major challenges in FO [30]. Table 2 shows the variations in the total dissolved solids (TDS) permeate and removal efficiencies obtained using two types of draw solutions, $0.05 \mathrm{M}$ EDTA-2Na alone and 0.05 M EDTA-2Na coupled with $15 \mathrm{mM} \mathrm{NP7}$ at an operating pressure of $80 \mathrm{psi}$. The results showed that the removal efficiencies of both draw solutions were high because of electrostatic repulsion between the negatively charged NF membrane and negatively charged H[EDTA $]^{3-}[31-33]$. However, the recovery of $0.05 \mathrm{M}$ EDTA-2Na coupled with $15 \mathrm{mM}$ NP7 (approximately 95\%) was higher than that of $0.05 \mathrm{M}$ EDTA-2Na alone (91\%). A gel layer formed when the NP surfactant was coupled with EDTA$2 \mathrm{Na}$, thus improving the recovery of the diluted draw solution by an NF system (Figure 10 (a)). A possible reason for this difference is that coupling NP7 with EDTA-2Na increased the size of particles in the draw solution, improving removal efficiency. As shown in Figure10 (b), the particle size distribution of $0.05 \mathrm{M}$ EDTA-2Na coupled with $15 \mathrm{mM}$ NP7 was measured to be approximately $954.2 \mathrm{~nm}$. This result demonstrated that a novel draw solution of EDTA-2Na coupled with NP7 can be easily recovered using NF membrane. The proposed FO/NF hybrid system is advantageous compared with the $\mathrm{FO} / \mathrm{RO}$ process because $\mathrm{FO} / \mathrm{RO}$ desalination requires high energy [34]. 


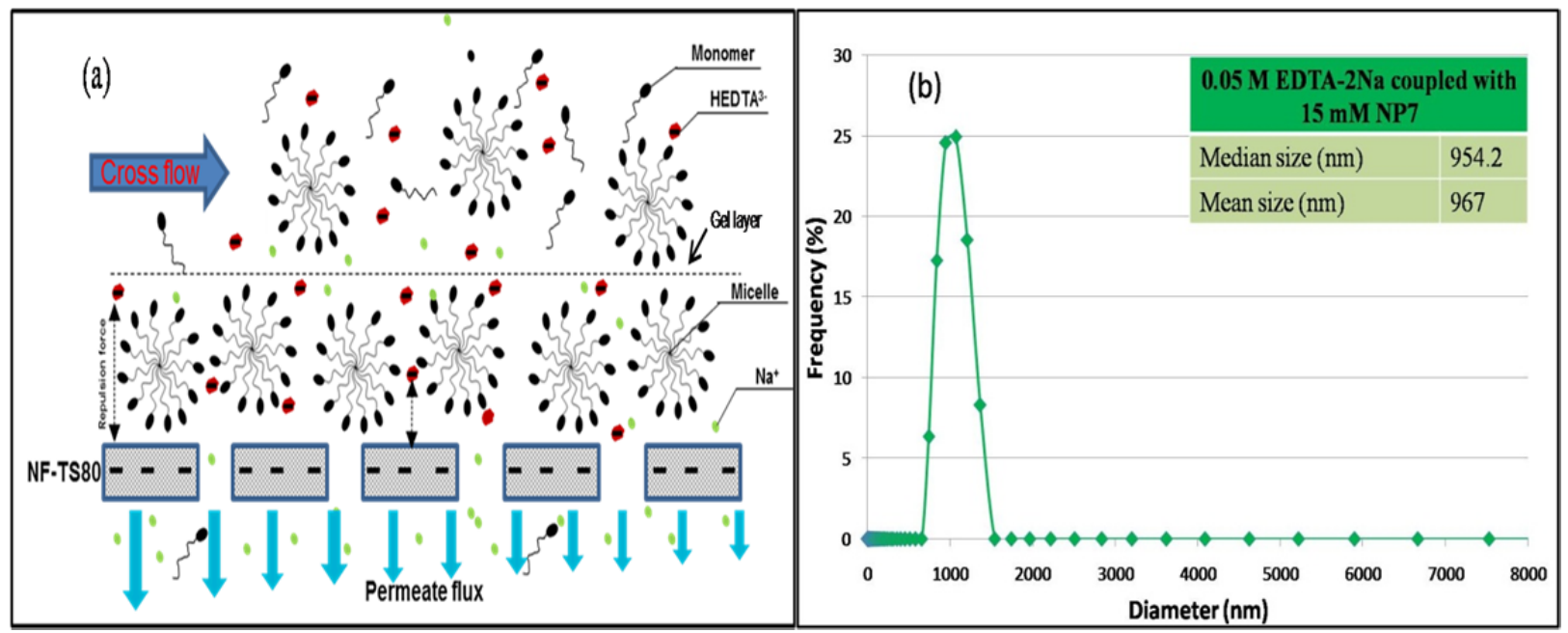

Figure.10. (a) Schematic illustration for recovery diluted draw solution by NF-TS80 membrane with presence of NP surfactant in draw solution, and (b) size distribution of $0.05 \mathrm{M}$ EDTA-2Na coupled with $15 \mathrm{mM} \mathrm{NP7}$ at $\mathrm{pH} 8$

\section{Conclusion}

Highly charged EDTA coupled with NP7 was used as an innovative draw solution to reduce the reverse salt flux in FO for the first time. A minimal reverse salt flux of $0.067 \mathrm{GMH}$ was obtained when $0.1 \mathrm{M}$ EDTA-2Na coupled with $15 \mathrm{mM} \mathrm{NP7}$ was used as the draw solution and DI water was used as the feed solution. Moreover, high water fluxes of 7.68 and 3.81 LMH were obtained when brackish water $(5 \mathrm{~g} / \mathrm{L} \mathrm{NaCl})$ and sea water $(35 \mathrm{~g} / \mathrm{L} \mathrm{NaCl})$ were used as the feed solution, respectively, and $1 \mathrm{M}$ EDTA-2Na coupled with $15 \mathrm{mM} \mathrm{NP7}$ was used as the draw solution. The NF-TS80 membrane was used to recover the diluted draw solution, and a high recovery efficiency of approximately 95\% was achieved. Using EDTA-2Na coupled with NP7 as the draw solution in FO provides a new promising method for future applications. 


\section{Reference}

1. Achilli, A., et al., The forward osmosis membrane bioreactor: A low fouling alternative to MBR processes. Desalination, 2009. 239(1-3): p. 10-21.

2. McCutcheon, J.R., R.L. McGinnis, and M. Elimelech, Desalination by ammonia-carbon dioxide forward osmosis: Influence of draw and feed solution concentrations on process performance. Journal of Membrane Science, 2006. 278(1-2): p. 114-123.

3. Petrotos, K.B. and H.N. Lazarides, Osmotic concentration of liquid foods. Journal of Food Engineering, 2001. 49(2-3): p. 201-206.

4. Garcia-Castello, E.M., J.R. McCutcheon, and M. Elimelech, Performance evaluation of sucrose concentration using forward osmosis. Journal of Membrane Science, 2009. 338(1-2): p. 61-66.

5. Seppala, A. and M.J. Lampinen, Thermodynamic optimizing of pressure-retarded osmosis power generation systems. Journal of Membrane Science, 1999. 161(1-2): p. 115-138.

6. Achilli, A., T.Y. Cath, and A.E. Childress, Power generation with pressure retarded osmosis: An experimental and theoretical investigation. Journal of Membrane Science, 2009. 343(1-2): p. 42-52.

7. Ge, Q., M. Ling, and T.-S. Chung, Draw solutions for forward osmosis processes: Developments, challenges, and prospects for the future. Journal of Membrane Science, 2013. 442(0): p. 225-237.

8. Chekli, L., et al., A review of draw solutes in forward osmosis process and their use in modern applications. Desalination and Water Treatment, 2012. 43(1-3): p. 167-184.

9. Achilli, A., T.Y. Cath, and A.E. Childress, Selection of inorganic-based draw solutions for forward osmosis applications. Journal of Membrane Science, 2010. 364(1-2): p. 233241.

10. Alnaizy, R., A. Aidan, and M. Qasim, Copper sulfate as draw solute in forward osmosis desalination. Journal of Environmental Chemical Engineering, 2013 (b). 1(3): p. 424430.

11. Kiriukhin, M.Y. and K.D. Collins, Dynamic hydration numbers for biologically important ions. Biophysical Chemistry, 2002. 99(2): p. 155-168.

12. Zhao, S., L. Zou, and D. Mulcahy, Brackish water desalination by a hybrid forward osmosis - nanofiltration system using divalent draw solute. Desalination, 2012. 284(0): p. 175-181.

13. Ling, M.M., K.Y. Wang, and T.S. Chung, Highly water-soluble magnetic nanoparticles as novel draw solutes in forward osmosis for water reuse. Industrial and Engineering Chemistry Research, 2010. 49(12): p. 5869-5876.

14. Ge, Q., et al., Hydrophilic superparamagnetic nanoparticles: Synthesis, characterization, and performance in forward osmosis processes. Industrial and Engineering Chemistry Research, 2011. 50(1): p. 382-388.

15. Ge, Q., et al., Exploration of polyelectrolytes as draw solutes in forward osmosis processes. Water Research, 2012. 46(4): p. 1318-1326.

16. Yen, S.K., et al., Study of draw solutes using 2-methylimidazole-based compounds in forward osmosis. Journal of Membrane Science, 2010. 364(1-2): p. 242-252.

17. Stone, M.L., et al., Switchable polarity solvents as draw solutes for forward osmosis. Desalination, 2013. 312(0): p. 124-129. 
18. Ge, Q., F. Fu, and T.-S. Chung, Ferric and cobaltous hydroacid complexes for forward osmosis (FO) processes. Water Research, 2014. 58(0): p. 230-238.

19. Sato, N., Y. Sato, and S. Yanase, Forward osmosis using dimethyl ether as a draw solute. Desalination, 2014. 349(0): p. 102-105.

20. Tian, E., et al., A study of poly (sodium 4-styrenesulfonate) as draw solute in forward osmosis. Desalination, 2015. 360(0): p. 130-137.

21. Hau, N.T., et al., Exploration of EDTA sodium salt as Novel Draw Solution in Forward Osmosis Process for Dewatering of High Nutrient Sludge. Journal of Membrane Science, 2014

22. Gadelha, G., et al., Assessment of micellar solutions as draw solutions for forward osmosis. Desalination, 2014. 354(0): p. 97-106.

23. Cartinella, J.L., et al., Removal of natural steroid hormones from wastewater using membrane contactor processes. . Environmental Science and Technology, 2006. 40(23): p. 7381-7386.

24. Tiraferri, A., et al., Relating performance of thin-film composite forward osmosis membranes to support layer formation and structure. Journal of Membrane Science, 2011. 367(1-2): p. 340-352.

25. Muherei, M.A., R. Junin, and A.B. Bin Merdhah, Adsorption of sodium dodecyl sulfate, Triton X100 and their mixtures to shale and sandstone: A comparative study. Journal of Petroleum Science and Engineering, 2009. 67(3-4): p. 149-154.

26. Fillipi, B.R., et al., Use of Micellar-Enhanced Ultrafiltration at Low Surfactant Concentrations and with Anionic-nonionic Surfactant Mixtures. Journal of Colloid and Interface Science, 1999. 213(1): p. 68-80.

27. Jin, X., et al., Rejection of pharmaceuticals by forward osmosis membranes. Journal of Hazardous Materials, 2012. 227-228(0): p. 55-61.

28. Tan, C.H. and H.Y. Ng, A novel hybrid forward osmosis - nanofiltration (FO-NF) process for seawater desalination: Draw solution selection and system configuration. Desalination and Water Treatment, 2010. 13(1-3): p. 356-361.

29. Su, J. and T.-S. Chung, Sublayer structure and reflection coefficient and their effects on concentration polarization and membrane performance in FO processes. Journal of Membrane Science, 2011. 376(1-2): p. 214-224.

30. Zhao, D., et al., Thermoresponsive copolymer-based draw solution for seawater desalination in a combined process of forward osmosis and membrane distillation. Desalination, 2014. 348(0): p. 26-32.

31. Schaep, J. and C. Vandecasteele, Evaluating the charge of nanofiltration membranes. Journal of Membrane Science, 2001. 188(1): p. 129-136.

32. Morao, A.I.C., A.M.B. Alves, and M.D. Afonso, Concentration of clavulanic acid broths: Influence of the membrane surface charge density on NF operation. Journal of Membrane Science, 2006. 281(1-2): p. 417-428.

33. Verliefde, A.R.D., et al., The role of electrostatic interactions on the rejection of organic solutes in aqueous solutions with nanofiltration. Journal of Membrane Science, 2008. 322(1): p. 52-66.

34. Bamaga, O.A., et al., Hybrid FO/RO desalination system: Preliminary assessment of osmotic energy recovery and designs of new FO membrane module configurations. Desalination, 2011. 268(1-3): p. 163-169. 